Sādhanā Vol. 28, Part 5, October 2003, pp. 945-955. ( Printed in India

\title{
Micro-machining of optical glasses - A review of diamond-cutting glasses
}

\author{
F Z FANG, X D LIU and L C LEE \\ Singapore Institute of Manufacturing Technology, 71 Nanyang Drive, \\ Singapore 638075 \\ e-mail: fzfang@SIMTech.a-star.edu.sg
}

\begin{abstract}
In order to diamond-turn optical glasses to a nanometric surface finish, it is critical to determine the transition point from brittle mode to ductile mode. This paper presents various experimental techniques to study this transition and discusses the mechanism of the surface generation. It has been recognized that tool wear is a serious issue in diamond turning of glasses. Thus, research in future should be concentrated on this field to enable the technology to be applied in commercial production.
\end{abstract}

Keywords. Diamond cutting; brittle-ductile transition; glass.

\section{Introduction}

The process of using a single point diamond tool (SPDT) can be used to fabricate a finished optical component on a precision machine under very precisely controlled machining and environmental conditions. Although the application of diamond turning for optical components was started in the 1960s, the technology attracted wider attention only in the mid-70s (Saito 1978). Frank et al (1978) made a comparison between diamond turning and conventional techniques for the fabrication of an off-axis parabola as shown in table 1 .

Single point diamond turning is now a well-established technology for the fabrication of aspheric optics on metals, but it is more advantageous if it can be successfully applied to glass and ceramic materials. The process is the natural extension of conventional machine tool technology to nanometre precision. SPDT utilizes large single diamonds sharpened to edge radius as fine as $100 \mathrm{~nm}$, sometimes even upto $20-40 \mathrm{~nm}$. When used with the preferred diamond turnable materials (copper, electrolysis nickel, and aluminium), surface roughness

Table 1. Diamond turning compared to conventional optical fabrication.

\begin{tabular}{lcc}
\hline Parameter & Ground and polished hard figure & Diamond turning \\
\hline Accuracy $(p-v)$ & $3 \mu \mathrm{m}$ & $0.6 \mu \mathrm{m}$ \\
Cost & $\$ 50,000$ & $\$ 4,000$ \\
Fabrication time & 12 months & 3 weeks \\
\hline
\end{tabular}




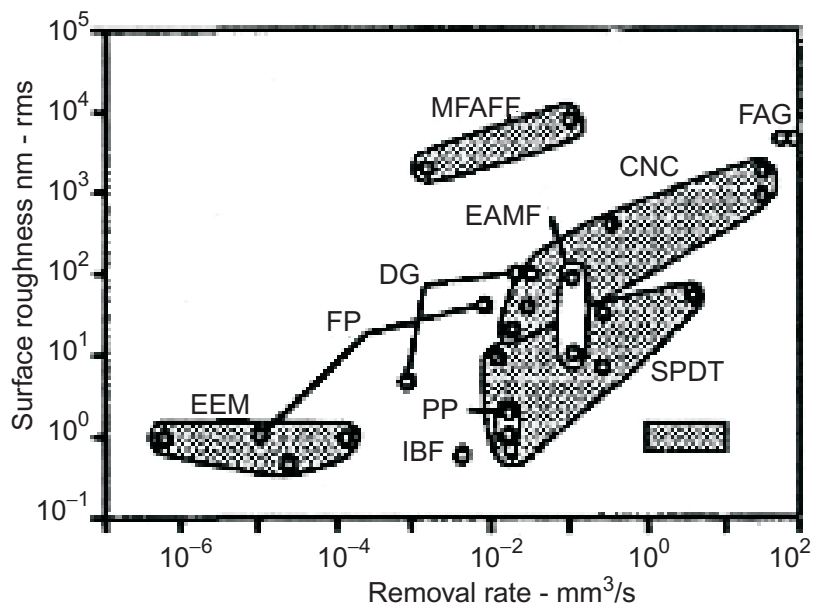

Figure 1. Comparison of surface roughness and removal rate achievable by various processes. FAG-conventional fixed abrasive grinding; $\mathrm{CNC}$-computer numerical control polishing; $\mathrm{FP}$ - float polishing; EEM-elastic emission machining; EJ - erosive jets; HP - chemical hydrodynamic polishing; MFAFF-magnetic field assisted fine finishing; EAMF-electrolytic abrasive mirror finishing; IBM-neutral ion beam figuring; PACE-plasma assisted chemical etching; SPDT-single point diamond turning; DG-ductile grinding (Stowers et al 1988).

values approaching $1 \mathrm{~nm}$ rms can be achieved. Figure 1 shows the interrelationship between achievable surface roughness and demonstrated volumetric removal rate (Stowers et al 1988).

Glass is a homogeneous material with a random, liquid-like (non-crystalline) molecular structure. The manufacturing process requires that the raw materials be heated to a temperature sufficient to be completely melted, and then be cooled rapidly, to become solid without crystallizing. Glass is hard and brittle, and includes various oxidized particles. In cutting optical glasses with diamond tools, new surfaces are produced by plastic deformation and brittle fracture occurs in a complex interaction between the glass, the environment, the tool and the machine. Moreover, the mechanisms involved in micro-cutting are not fully understood, since many parameters and properties are involved (Komanduri 1996; Paul \& Evans 1996).

It is noticed that most of these properties are influenced by temperature (Schinker et al 1987). Owing to these difficulties, the progress in techniques of cutting optical glasses to nanometric surface finish has been relatively slow. This paper reviews the diamond turning of optical glasses, present the latest research results and enumerates the major problems in the field.

\section{Brittle-ductile transition}

\subsection{Indentation}

A basic approach to study brittle-ductile transition is to use indentation. In contrast to metals, which react with flow processes both under external compressive or tensile loading, the brittle material glass, under the action of hydrostatic compressive stresses, viscously deforms only in microscopically small regions at temperatures below the softening point $T s$. Schinker et al (1991) studied the difference in the flow behaviour of metals and glasses under hydrostatic 


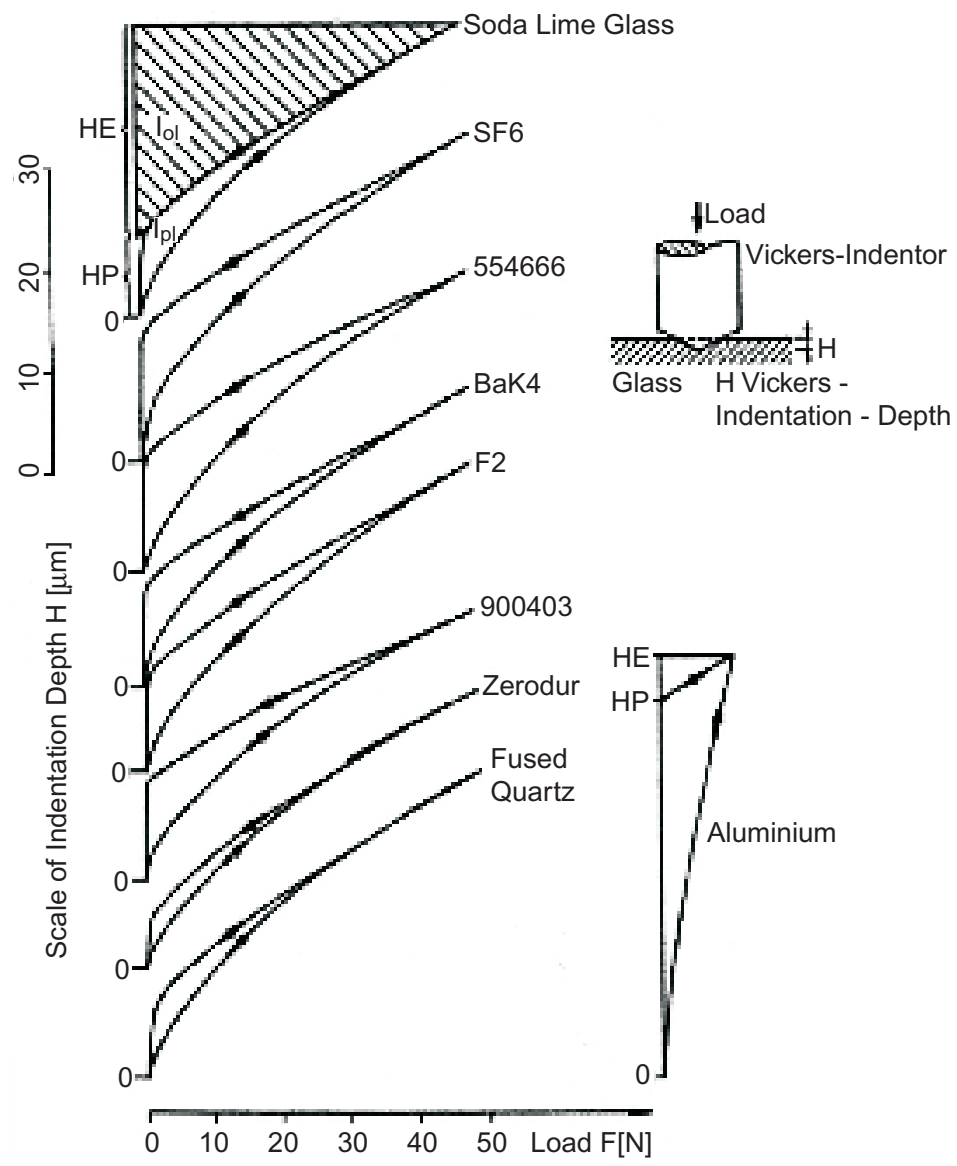

Figure 2. Load-penetration curves for different glasses. The comparison indicates high plastic deformation for aluminium even under a low load. The arrows indicate the loading and unloading phases respectively (Schinker \& Doll 1987).

compression from the load-penetration diagrams (see figure 2). These curves were obtained by vertical, quasistatic penetration of a Vickers (square-based pyramid) diamond into the surface of the material, whereby the force $F$ and the penetration depth $H$ were continuously monitored during both loading and unloading. In contrast to aluminum, which reacts to the penetration force with strong flow (a compressive force $F=10 \mathrm{~N}$ causes a remaining impression depth $H P=36 \mu \mathrm{m})$, the flow behaviour of the glasses presented here, which have extreme variations in their mechanical behaviour, is characterized by a small remaining impression depth $H P$ and a high elastic recovery $H E$. The values of the impression depth $H P$ of the glasses even at the relatively much higher penetration force of $50 \mathrm{~N}$ lie between about $5 \mu \mathrm{m}$ (glass-ceramic Zerodur) and $13 \mu \mathrm{m}$ (phosphate glass 554666). The fact that brittle fracture occurs even in this method of loading can be seen clearly only in the diagram for the glass-ceramic Zerodur, where a clear jump in the penetration depth occurs in the loading phase as a result of fracture initiation. All of the other glasses show microscopic crack formation to different extent and in different ways during loading in the high-load region; but in any case, even at low final loads crack formation occurs during unloading. 


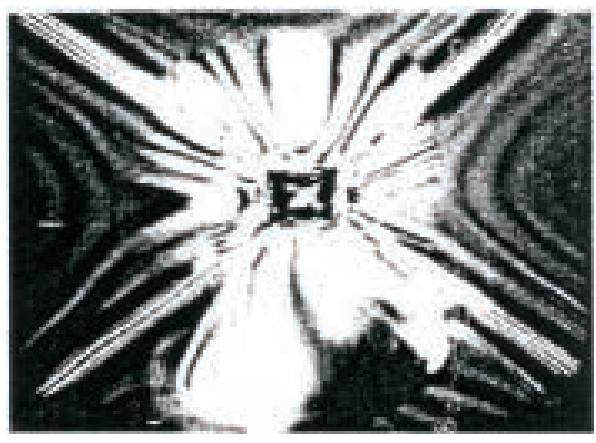

Figure 3. Indentation of glass showing brittle fracture (Gee et al 1991).

This characterisation of the quasistatic flow and fracture behaviour of inorganic glasses at room temperature is in accordance with the observation of critical transition depth of penetration for plastic/brittle material removal at high speed grooving which also depends on type of glass and diamond tool geometry. Figure 3 shows a classical result when subject to a Vickers indenter. Radial cracks normal to the surface radiate from the comers (initially) and a vent opens up at the apex (bottom) of the indentation. Lateral cracks propagate parallel to the surface, particularly on removal of the load.

Fang \& Zhang (2003) conducted a nano-indentation (triangle-based pyramid) analysis on BK7 glass. A load $F$ pushes the indenter into the surface to a depth of $H$. This induces a plastic zone to form in the high stress zone under the indenter tip. When the indenter (or the cutting tool) moves away, residual stress remains at the plastic zone boundary which, if large enough, results in median and lateral cracks. However, when the indenter load and then the scale of the indentation are reduced to the order of $0.1 \mathrm{~N}$ and one micrometre, respectively, it is observed that the adjacent material does not crack, indicating that the plastic regime is not evident at larger scales (figure 4a). A number of glassy, ceramic and crystalline materials manifest such effects in the submicrometre region. It is also obvious from the details in the photograph that plastic flow is involved in indentation, for instance, the permanent "pile-up" along the indentation in figures $4 \mathrm{~b}$ and $\mathrm{c}$.

\subsection{Single point scratching}

A natural extension of indentation study is to apply lateral motion of the loaded indenter/workpiece. This can be done either under fixed load or fixed geometry conditions. Figure 5 shows a schematic of single point scratching by diamond indenter, where $w$ is the width of the indentation cavity, $d$ is the depth of scratching, $d_{p}$ is the depth of the plastic zone, $h$ is the height of scratching, $l$ is the length of the scratching groove, $F n$ is the normal load, $F t$ is the scratching force and $F$ is the resultant force. If the indentation at a particular load or depth is critical with manifest radial and lateral cracks then the resultant linear "cut" will be likewise.

\subsection{Taper grooving}

Taper cutting experiments with increasing depth of cut was performed on BK7 glass (see figure 6). The experiments were carried out on an ultra-precision turning machine. Figure 7 shows a plunge-cut result using a $0^{\circ}$ nominal rake angle tool. Ductile cutting can be obtained when depth of cut is below a threshold value (Fang \& Yuan 1999; Fang \& Chen 2000).

While analysing the surface texture generated by taper grooving, different micro-topographs were found depending on the critical undeformed chip thickness $t_{c}$. If the undeformed chip 

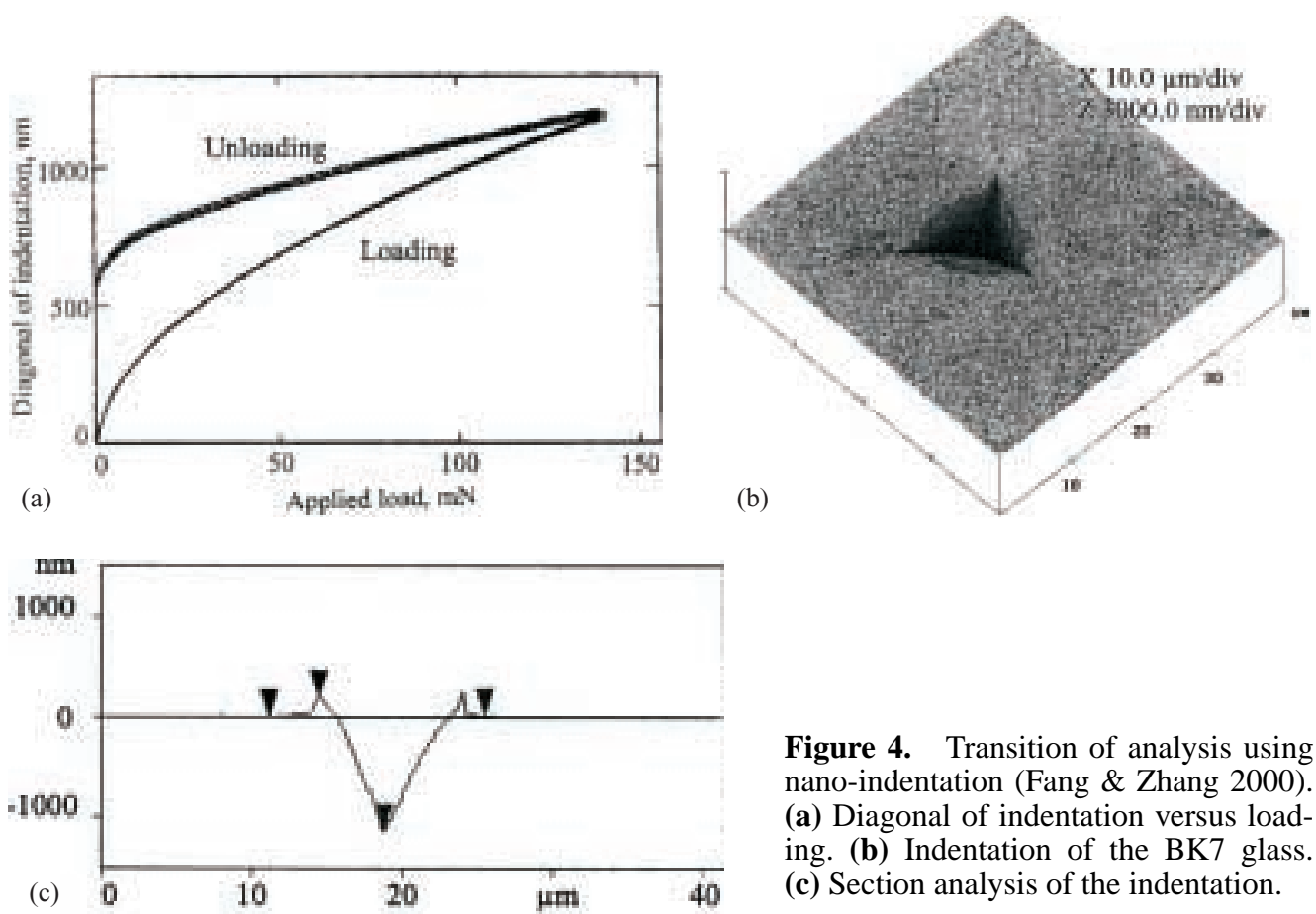

Figure 4. Transition of analysis using nano-indentation (Fang \& Zhang 2000). (a) Diagonal of indentation versus loading. (b) Indentation of the BK7 glass. (c) Section analysis of the indentation.

thickness $t$ is greater than this threshold (in this case, $t_{c}$ is about $62 \mathrm{~nm}$ ), sections characterized by increased fractures and a markedly different micro-topograph (figure 8) appear in all grooves. As long as $t$ is smaller than $t_{c}$, all grooves exhibit a very smooth micro-topograph (ductile cutting). The same observation is noted with different diamond tools and cutting speeds. An additional interesting result obtained occasionally is a mini-triangular shaped thin

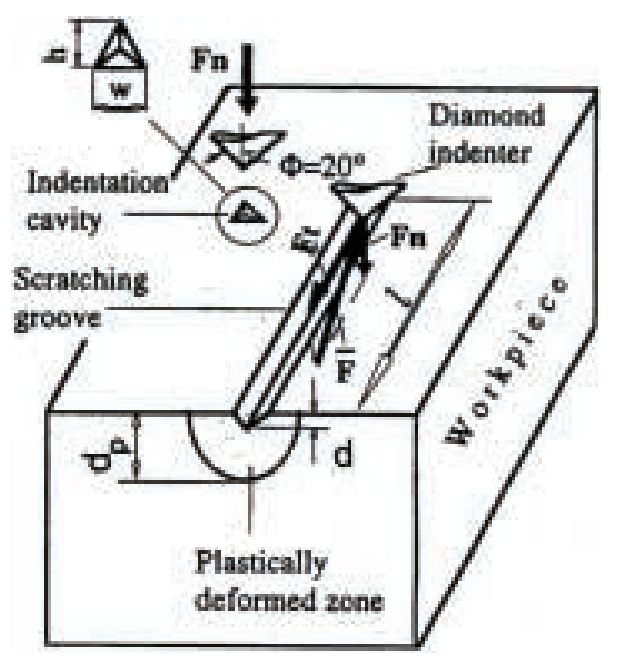

Figure 5. Schematic of single-point scratching (Chouanine et al 1997). 


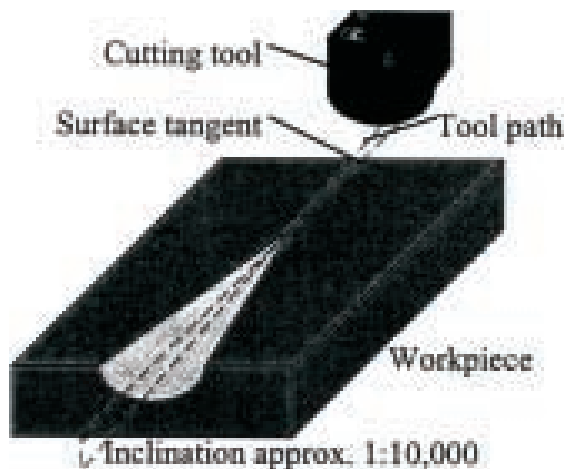

CInclination approx, 1:10,000
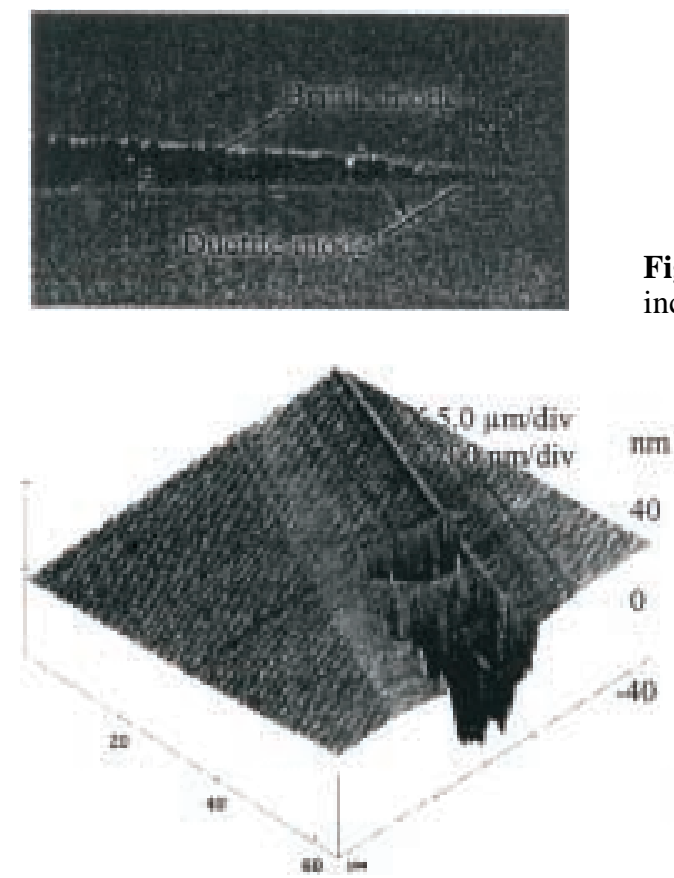

Figure 6. Experimental set-up of inclined plunge cut (Fang 1998).

Figure 7. Brittle and ductile modes analysed by inclined plunge-cut (Fang 1998).

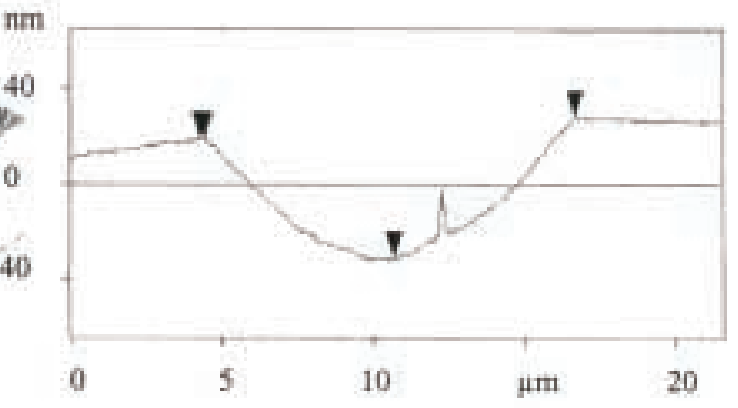

Figure 8. AFM photograph of the BK7 plunge-cut groove (Fang \& Venkatesh 1998). (a) AFM micro-topography reveals brittle fractures at the bottom, (b) Sectional analysis reveals ductile cutting with a mini triangular shaped thin standing structure.

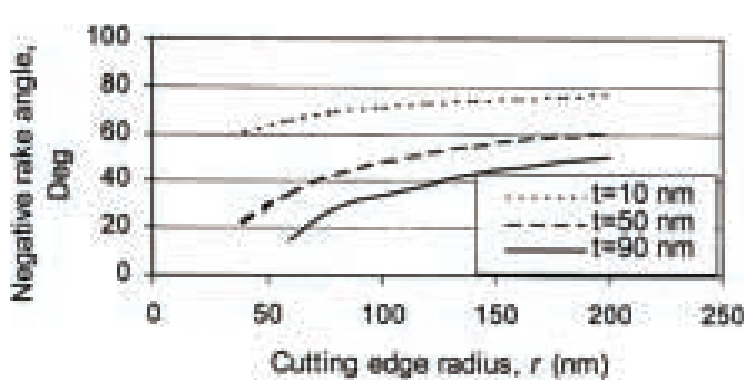

Figure 9. Tool rake variations with cutting edge radii and undeformed chip thickness (Fang \& Chen 2000). 
standing structure left on the groove due to the cutting edge micro-chipping (figure 8c). This is another piece of evidence to show that ductile cutting can be achieved under undeformed chip thickness less than a critical value.

The critical depth of cut from brittle mode to ductile mode transition can be increased by means of heat-assisted cutting or ultrasonic vibration-assisted cutting. This will be discussed in $\S 4$.

\section{Surface generation}

In machining glasses, a negative rake angle face is necessary to produce sufficient hydrostatic compressive stress in the cutting zone. This compressive stress makes the material transit from the brittle regime to a ductile regime. In conventional machining, the cutting edge radius of carbide tools can be considered to be sharp as the undeformed chip thickness is substantially larger than the radius value. When the cutting edge radius is larger than the undeformed chip thickness in ultra-precision machining of brittle materials, even though the actual rake angle is $0^{\circ}$, the effective rake angle $\gamma_{e}$ is a large negative value. Figure 9 shows that the effective rake angle varies with the tool edge radii and undeformed chip thickness (Fang et al 2002). With an increase in cutting edge radius and a decrease in undeformed chip thickness, the rake angle of the tool becomes more negative. However, an extreme negative rake with large edge radius has a negative effective rake that could be much higher, creating more ploughing and sliding instead of chip formation.

Figure 10 shows the glass surfaces analysed by atomic force microscopy (Fang \& Chen 2000). The work material is ZKN7 glass, which is a silicate glass with a Knoop hardness of $530 \mathrm{~kg} / \mathrm{rnm}^{2}$ and a high softening point of $721^{\circ} \mathrm{C}$. During the turning of the glass, a number of cutting conditions were tried to get better surfaces. A single crystal diamond tool with a rake angle of $0^{\circ}$ and a nose radius $1.00 \mathrm{~mm}$ was used to turn the glass. Figure 10 shows that (a) brittle mode, (b) semi-ductile mode and (c) ductile mode can be obtained under different cutting conditions with the spindle speed of $1400 \mathrm{rpm}$, feed rate of $1.4 \mu \mathrm{m} / \mathrm{r}$, and depth of cut of $2 \mu \mathrm{m}, 1.2 \mu \mathrm{m}$ and $0.6 \mu \mathrm{m}$ respectively. Puttick et al (1989) and Chao \& Gee (1991) observed continuous chips when cutting soda lime glass as shown in figure 11.

Although ductile mode cutting can be achieved, the adoption of the technology in practical use due to the rapid tool wear continues to present problems. Figure 12 shows that the maximum flank wear, $V_{\mathrm{bmax}}$, is around $70 \mu \mathrm{m}$ after a cutting distance of $4000 \mathrm{~m}$. One important reason for this could be that with decrease in the undeformed chip thickness, the distribution of movable dislocations in micro-structures approaches zero and cutting forces have to overcome the very large atomic bonding forces within the micro-structures.

\section{Tool life improvement}

\subsection{Ultrasonic vibration assisted cutting}

Due to serious problems with tool life, extensive studies have been conducted. One approach to prolonging tool life is to apply ultrasonic vibration to the diamond cutting tool. The idea is that with vibration during cutting, the lubricant can easily penetrate the cutting zone. Also, the shatter contact time between the cutting tool and work material improves the tool life. In addition to increasing the tool life, another advantage of the use of ultrasonic vibrationassisted cutting is that the critical depth of cut can be increased. Moriwaki et al (1992) carried 
(a)

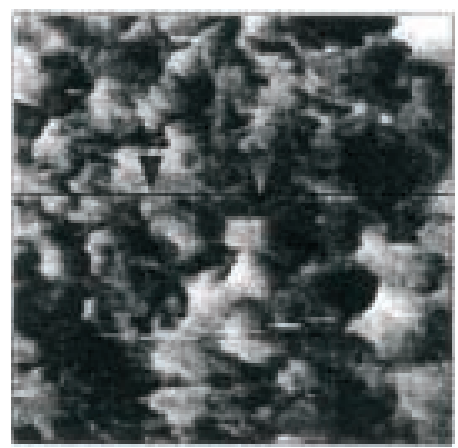

(c)

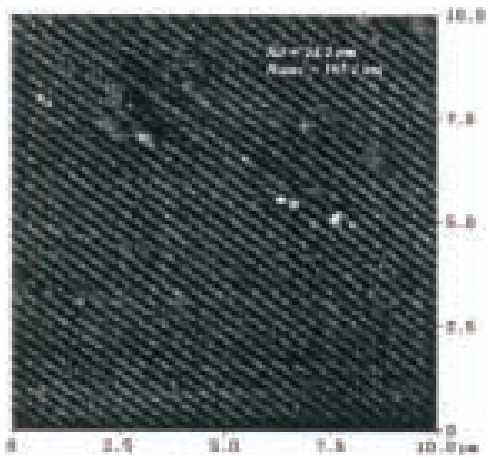

(b)

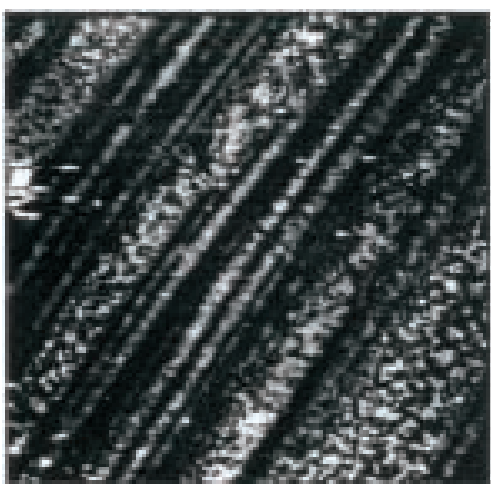

Figure 10. Surface analysis over an area of $10 \times 10 \mu \mathrm{m}^{2}$ (Fang \& Chen 2000).

out experiments to study the critical depth of cut. Figure 13 shows the effect of the maximum vibrating speed of the tool on the critical depth of cut. When the maximum vibrating speed exceeds about ten times the cutting speed, the critical depth of cut increases by around sevenfold that obtained with a conventional stationary tool. The main reason for the improvement of critical depth of cut by the ultrasonic vibrating cutting can be explained as follows. The intermittent cutting due to the ultrasonic vibration causes separation of the rake face of the tool from the chip and introduces the aerodynamic lubrication between the tool rake and the chip. Hence, the friction at the tool-chip interface is reduced. This causes reduction in the instantaneous cutting force as well as the average cutting force, which is naturally reduced

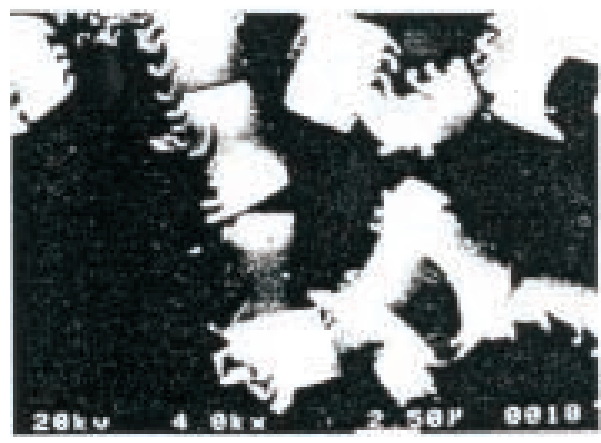

Figure 11. Continuous glass chips (Chao \& Gee 1991). 


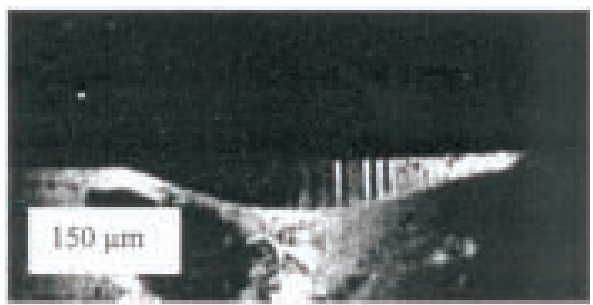

Figure 12. Flank wear in cutting glass.

because of the intermittent cutting. As the force to initiate brittle fracture is reduced, the critical depth of cut is consequently increased.

The increase in the critical depth of cut is advantageous from the viewpoints of efficiency and operation.

\subsection{Heat assisted cutting}

With increases in temperature, glasses soften and the materials become less brittle. In accordance with this fact, investigations on the heat-assisted cutting of glasses were conducted. Brehm et al (1979) applied a slit-burner and a point burner as heaters to elevate the workpiece temperature as shown in figure 14. The slit burner has a slit which is at least as long as the workpiece. The heat output can be preset. The point burner directed just above the tool tip. The heat output is continuously adjustable. The latter is part of a feedback system controlled by an Ircon (infrared radiation) temperature measurement detector and adjusted by a variable gas-flow system.

The burners heat the workpiece up to the glass removal condition beyond the glass transition temperature. The point burner at the same time acts locally in improving the surface finish without geometrically disturbing the bulk of the glass. This implies that moderate annealing has to be applied afterwards to prevent stress, i.e. index variations in the workpiece. Single crystal diamond is the only tool material applied in mirror finishing of metals. At elevated

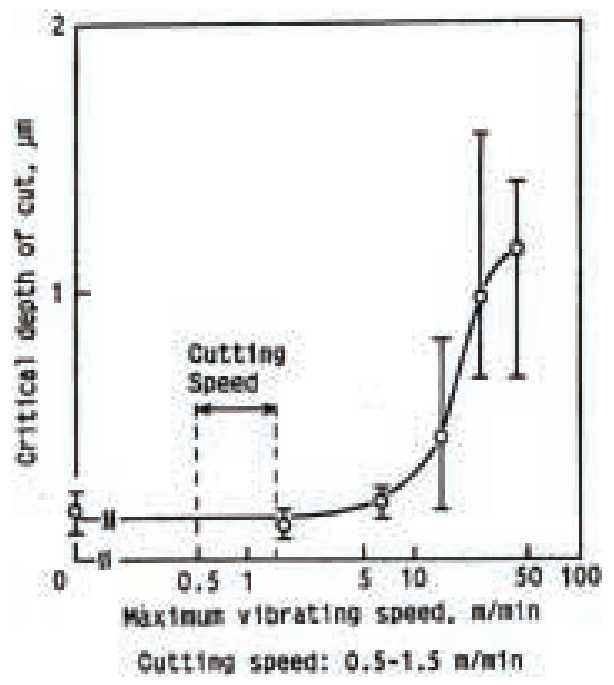

Figure 13. Effect of tool vibration speed on critical depth of cut (Moriwaki et al 1992). 


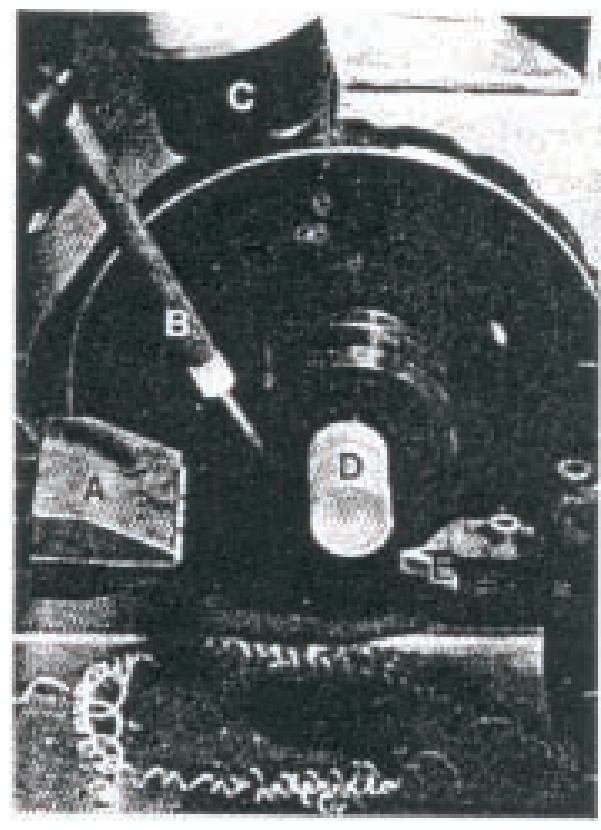

Figure 14. Set-up of burner-heating glass. A-slit burner, $\mathrm{B}$-point burner, $\mathrm{C}$-radiation control, $\mathrm{D}$ workpiece and $\mathrm{E}-$ tool (Brehm et al 1979).

temperatures, however, diamond transforms into graphite. Brehm et al (1979) conducted experimental studies on various tool materials. Among them, hafnium nitride was found to be by far the best tool material for this application due to its properties maintained in high temperatures. Apart from the burners, laser is an alternative to heat the machining area due to its good focussing performance in a special area. $\mathrm{CO}_{2}$ laser was used with adjustable power of laser beam to control the elevated temperature on BK7 glass. Experimental results show that owing to the thermal stress from the steep gradient of the temperature, cracks occur. The recommendation for future study is that two laser beams, one with a small focussing area and the other with a big focussing area should be used to form two overlapping hot areas (Fang 2000). This reduces the temperature difference between the heated and non-heated areas and decreases the thermal stress leading to fewer cracks.

\section{Summary}

Optical glass, being hard and brittle, is one of the most difficult to cut materials. An important area in investigating glass machining is the study of the transition from brittle to ductile mode. Three methods were discussed in the paper. Taper grooving was found to be an effective way to study the transition as it presents more direct information. Although nanometric surface finishes can be obtained, the tool life is still a major obstacle in the use of diamond cutting technology commercially in production.

\section{References}

Brehm R, van Dun K, Teunissen J C G, Haisma J 1979 Transparent single-point turning of optical glass. 1(4): 207-213 
Chao C L, Gee A E 1991 Material removal mechanism involved in the single-point diamond turning of brittle materials. Proceedings of ASPE Annual Meeting pp 112-115

Chouanine L, Eda H, Shimizu J 1997 Analytical study on ductile-regime scratching of glasses using sharply pointed tip diamond indenter. Int. 3. Japan Soc. Prec. Eng. 31(2): 109-114

Fang F Z 1998 Nano-turning of single crystal silicon. J. Mater. Process. Technol. 82: 98-101

Fang F Z 2003 An experimental study of optical glass machining. Int. J. Mach. Tools Manuf. (in press)

Fang E Z, Chen L 2000 Ultra-precision cutting for ZKN glass. Ann. CIRP 49(1): 17-20

Fang F Z, Venkatesh V C 1998 Diamond cutting of silicon with nanometric fmish. Ann. CIRP 47(1): 45-49

Fang F Z, Yuan Z J 1999 Ultra-precision cutting for gallium arsenide. Proc. ASPE Annual Meeting: pp 62-66

Fang F, Zhang G X 2000 Monthly technical report of soften-machining technology (January). Singapore Inst. Manuf. Technol.

Fang F Z, Venkatesh V C, Zhang G X 2002 Diamond turning of soft semiconductors to obtain nanometric rnirror surfaces. Int. J. Adv. Manuf. Technol. 19: 637-641

Frank A M, Bryan J B, Clouser R W 1978 Quick fast off-axis parabolas. Appl. Opt. 17: 671-673

Gee A E, Spragg R C, Puttick K E, Rudman M R 1991 Single-point diamond form-finishing of glasses and other macroscopically brittle materials, SPIE 1573: 39-48

Komanduri R 1996 On material removal mechanisms in finishing of advanced ceramics and glasses. Ann. CIRP 45(1): 509-514

Moriwaki T, Shamoto E, Inoue K 1992 Ultra-precision ductile cutting of glass by applying ultrasonic vibration, Ann. CIRP 41(1): 141-144

Paul E, Evans C J 1996 Chemical aspects of tool wear in single point diamond turning, Precision Engineering, 18(1): 4-19

Puttick K E, Rudman M R, Smith K J, Franks A, Lindsey K 1989 Single-point diamond machining of glasses. Proc. R. Soc. London A426: 19-30

Saito T T 1978 Diamond turning of optics: the past, the present, and the exciting future. Opt. Eng. 17(6): 570-573

Schinker M G 1991 Subsurface damage mechanisms at high-speed ductile machining of optical glasses. Prec. Eng. 13/3: 208-218

Schinker M G, Doll W 1987 Turning of optical glasses at room temperature. SPIE 802: 70-80

Stowers I F, Komanduri R, Baird E D 1988 Review of precision surface generating processes and their potential applications to the fabrication of large optical components. SPIE 0966: 62-73 